\title{
Characterization of primaquine imidazolidin-4-ones with antimalarial activity by electrospray ionization-ion trap mass spectrometry
}

\author{
Nuno Vale ${ }^{\mathrm{a}}$, Rui Moreira ${ }^{\mathrm{b}}$, Paula Gomes ${ }^{\mathrm{a}, *}$ \\ ${ }^{a}$ Centro de Investigação em Química da Universidade do Porto, Departamento de Química, Faculdade de Ciências, \\ Universidade do Porto, R. Campo Alegre 687, P-4169-007 Porto, Portugal \\ ${ }^{\mathrm{b}}$ Centro de Estudos de Ciências Farmacêuticas, Faculdade de Farmácia, \\ Universidade de Lisboa, Av. Prof. Gama Pinto, P-1649-019 Lisboa, Portugal
}

Received 19 November 2007; accepted 5 December 2007

Available online 14 December 2007

\begin{abstract}
The extensive characterization by electrospray ionization-ion trap mass spectrometry (ESI-MS ${ }^{n}$ ) of 20 imidazolidin-4-ones derived from the antimalarial primaquine was well obtained. These compounds are being under investigation as potential antimalarials, as they have been previously found to be active against rodent $P$. berghei malaria and to be highly stable under physiological conditions. Experiments by collision-induced dissociation (CID) in the nozzle-skimmer region or by tandem-MS have shown the title compounds to be remarkably stable. Mechanisms are proposed to explain the major fragmentations observed in ESI-MS ${ }^{n}$ experiments. Overall, this work represents an unprecedented contribution to a deeper insight into imidazolidin-4-one antimalarials based on a classic 8-aminoquinolinic scaffold. Data herein reported and discussed may be an useful guide for future studies on therapeutically relevant molecules possessing either the 8-aminoquinoline or the imidazolidin-4-one motifs.

(C) 2007 Elsevier B.V. All rights reserved.
\end{abstract}

Keywords: 8-Aminoquinoline; Antimalarial; ESI-MS ${ }^{n}$; Fragmentation; Imidazolidin-4-one

\section{Introduction}

The diverse analytical methods focused on the antimalarial primaquine $(\mathrm{PQ}, \mathbf{1}$, Scheme 1) or its analogues have been so far targeted at pharmacokinetics studies and metabolite analysis [1-9] or isomer separation/characterization [10,11]. The application of molecular modeling studies associated to voltammetric techniques showed to be an important way to understand the redox mechanism of electro-active drugs where aminoquinolines (AQs) such as PQ are included [7]. Two classes of AQs were investigated by infrared spectrometry to assess their geometry and coordination ability [6]. UV absorption and circular dichroism (CD) have also been used to investigate interactions between heparin and several quinolines [6]. Studies with HPLC are also currently used to characterize therapeutically relevant $\mathrm{AQs}$, including $\mathrm{PQ}$ and its metabolites [1-3]. Other analytical tools to study PQ and its derivatives have included fast atom bombardment mass spectral analysis

\footnotetext{
* Corresponding author. Tel.: +351 220402563; fax: +351 220402659 .

E-mail address: pgomes@fc.up.pt (P. Gomes).
}

of three new PQ oxidation products [4] or enantioselective capillary electrophoresis for the simultaneous determination of $\mathrm{PQ}$ and its main metabolite, carboxyprimaquine, in rat liver mitochondrial fraction [5]. Supercritical fluid chromatography-mass spectrometry (SFC-MS) was used to achieve shorter analysis times while having good resolution between PQ (free base), PQ diphosphate and the positional isomer quinocide, as well as to elucidate additional information about differences in their MS fragmentation patterns [8]. PQ and its isomers have also been identified by liquid chromatography-mass spectrometry (LC-MS) [10].

Electrospray ionization-mass spectrometry (ESI-MS) analysis, introduced by Yamashita and Fenn [12a,b], was described for the identification of NPC 1161, another antimalarial 8-AQ, and its metabolites in biological samples [9]. ESI-MS techniques are relevant in many research and development $(\mathrm{R} \& \mathrm{D})$ areas [13-19], from food chemistry to the pharmaceutical industry [20-37]. Detailed structural information on drugs and related molecules can be obtained by resorting to cone voltage fragmentation with single MS instrumentation, to collisionally induced dissociation (CID) with triple quadrupole MS instruments, to $\mathrm{MS}^{n}$ techniques using quadrupole ion-trap instrumentation or 
<smiles>COc1cc(NC(C)CCCN)c2ncccc2c1</smiles>

1<smiles>[Y]N[C@H]([R])C(=O)NCCCC(C)Nc1cc(O[Ga])cc2cccnc12</smiles>

Scheme 1. Synthetic route to imidazolidin-4-one derivatives of PQ [40]: (i) BocAAOH + DCCI/HOBt or BocAAOSu (see text), DCM, $0{ }^{\circ} \mathrm{C} \rightarrow$ r.t.; (ii) neat TFA, r.t.; $30 \%$ aq. $\mathrm{Na}_{2} \mathrm{CO}_{3}$ until $\mathrm{pH} 10$, extraction with $\mathrm{CHCl}_{3}$; (iii) $\mathrm{R}^{2}(\mathrm{C}=\mathrm{O}) \mathrm{R}^{3}$, molecular sieves, refluxing $\mathrm{MeOH}$.

to time-of-flight mass spectrometry (ToF-MS) [31,32,35]. ESI$\mathrm{MS}^{n}$ studies of antimalarial compounds as bisthiazolium or quinolines can be found on reports by Nicolas et al. [38] or Smyth et al. and O'Donnell et al. [34,39], respectively. However, ESI-MS studies contributing to the development of antimalarials are scarce. Over the past few years, our research group has been working on imidazolidin-4-one derivatives of $\mathrm{PQ}$ as potential highly bioavailable antimalarials [40-42]. These imidazolidin-4-ones $(\mathbf{4}$, Scheme 1$)$ are stable at physiological $\mathrm{pH}$ and temperature, both in isotonic buffer and in human plasma, evidencing a weak conversion into their PQ $\alpha$-aminoamide precursors (3, Scheme) with half-lives ranging from 9 to 30 days [41,42]. Moreover, these imidazolidin-4-one derivatives of PQ displayed gametocytocidal activity comparable or superior to that of the parent drug [41].

We now wish to report the characterization of $20 \mathrm{PQ}$-derived imidazolidin-4-ones 4 (Table 1) by ESI-MS ${ }^{n}$ techniques. This contributes to a deeper insight into the properties of these bio- logically relevant 8-AQs, through knowledge of their stability and fragmentation mechanisms under the gas-phase conditions of the ESI-MS ${ }^{n}$ experiments.

\section{Experimental}

\subsection{Chemical synthesis}

The synthesis and spectral (NMR, HRMS) characterization of 14 out of the 20 imidazolidin-4-ones 4 covered by the present study have been reported elsewhere [40]. The procedure for the initial condensation of $\mathrm{PQ}$ with a Boc-protected amino acid (BocAAOH) in dichloromethane (DCM) was slightly changed with respect to our previous report [40], as reaction times can be dramatically reduced through utilization of the succinimide ester of the amino acid, instead of using a dicyclohexylcarbodiimide (DCCI)/1-hydroxybenzotriazole (HOBt)-mediated condensation. The six new derivatives were obtained by the

Table 1

PQ and derived imidazolidin-4-ones studied; average $\mathrm{m} / \mathrm{z}$ values for the main species detected in the full-MS spectral analysis of compounds 1, 3.2 and 4.1-4.20 are also given for comparison

\begin{tabular}{|c|c|c|c|c|c|c|}
\hline Compound & $\mathbf{R}_{1}$ & $\mathbf{R}_{2}$ & $\mathbf{R}_{3}$ & $\mathrm{MW}\left(\mathrm{g} \mathrm{mol}^{-1}\right)$ & $m / z[M+\mathrm{H}]^{+}$ & $\overline{m / z[M+\mathrm{Na}]^{+}}$ \\
\hline 4.2 & $-\mathrm{CH}_{3}$ & $-\mathrm{CH}_{3}$ & $-\mathrm{CH}_{3}$ & 370.49 & 371.93 & 393.60 \\
\hline 4.3 & $-\mathrm{CH}\left(\mathrm{CH}_{3}\right)_{2}$ & $-\mathrm{CH}_{3}$ & $-\mathrm{CH}_{3}$ & 398.45 & 399.93 & 422.00 \\
\hline 4.5 & $-\mathrm{CH}_{2} \mathrm{CH}\left(\mathrm{CH}_{3}\right)_{2}$ & $-\mathrm{CH}_{3}$ & $-\mathrm{CH}_{3}$ & 412.57 & 414.07 & 436.06 \\
\hline 4.6 & $-\mathrm{CH}\left(\mathrm{CH}_{3}\right) \mathrm{CH}_{2} \mathrm{CH}_{3}$ & $-\mathrm{CH}_{3}$ & $-\mathrm{CH}_{3}$ & 412.57 & 414.07 & 436.33 \\
\hline 4.7 & $-\mathrm{CH}\left(\mathrm{CH}_{3}\right)_{2}$ & \multicolumn{2}{|c|}{$-\left(\mathrm{CH}_{2}\right)_{4}-$} & 424.58 & 425.93 & 447.80 \\
\hline 4.10 & $-\mathrm{CH}\left(\mathrm{CH}_{3}\right)_{2}$ & \multicolumn{2}{|c|}{$-\left(\mathrm{CH}_{2}\right)_{2} \mathrm{CH}\left(\mathrm{CH}_{3}\right)\left(\mathrm{CH}_{2}\right)_{2}-$} & 452.63 & 453.93 & 476.33 \\
\hline 4.11 & $-\mathrm{H}$ & \multicolumn{2}{|c|}{$-\left(\mathrm{CH}_{2}\right)_{2} \mathrm{CH}\left(\mathrm{CH}_{3}\right)\left(\mathrm{CH}_{2}\right)_{2}-$} & 410.55 & 412.33 & 433.80 \\
\hline 4.12 & $-\mathrm{CH}_{3}$ & \multicolumn{2}{|c|}{$-\left(\mathrm{CH}_{2}\right)_{2} \mathrm{CH}\left(\mathrm{CH}_{3}\right)\left(\mathrm{CH}_{2}\right)_{2}-$} & 424.58 & 425.80 & 448.07 \\
\hline 4.13 & $-\mathrm{CH}_{3}$ & \multicolumn{2}{|c|}{$-\left(\mathrm{CH}_{2}\right)_{6-}$} & 424.58 & 425.67 & 447.93 \\
\hline 4.14 & $-\mathrm{CH}_{2} \mathrm{CH}\left(\mathrm{CH}_{3}\right)_{2}$ & \multicolumn{2}{|c|}{$-\left(\mathrm{CH}_{2}\right)_{6}-$} & 466.66 & 467.87 & 490.93 \\
\hline 4.15 & $-\mathrm{CH}\left(\mathrm{CH}_{3}\right) \mathrm{CH}_{2} \mathrm{CH}_{3}$ & \multicolumn{2}{|c|}{$-\left(\mathrm{CH}_{2}\right)_{6-}$} & 466.66 & 468.00 & 490.20 \\
\hline 4.20 & $-\mathrm{CH}_{2} \mathrm{Ph}$ & \multicolumn{2}{|c|}{$-\left(\mathrm{CH}_{2}\right)_{4}-$} & 472.62 & 474.07 & 495.93 \\
\hline 1 & - & - & - & 259.35 & 260.80 & $-^{\mathrm{a}}$ \\
\hline 3.2 & $-\mathrm{CH}_{3}$ & - & - & 330.42 & 331.23 & 354.00 \\
\hline
\end{tabular}

\footnotetext{
${ }^{\text {a }}$ Sodium adducts were never observed in the full-MS spectra of primaquine.
} 
Table 2

Main species (relative abundance $\geq 20 \%$ ) detected in the analyses in the nozzle-skimmer region

\begin{tabular}{|c|c|c|c|c|c|c|c|c|c|c|c|c|c|c|c|c|c|c|c|c|c|c|}
\hline \multirow{2}{*}{$\frac{\text { Species }}{[M+\mathrm{H}]^{+} \text {and/or }[M+\mathrm{Na}]^{+}}$} & \multirow{2}{*}{$\frac{V_{\mathrm{s}} \mathrm{CID}}{70}$} & \multicolumn{21}{|c|}{ Compounds on whose spectra the species was observed } \\
\hline & & & 4.2 & 4.3 & & & 4.6 & 4.7 & 4.8 & 4.9 & 4.10 & 4.11 & 4.12 & 4.13 & 4.14 & 4.15 & 4.16 & 4.17 & 4.18 & 4.19 & 4.20 & 1 \\
\hline & 80 & & 4.2 & 4.3 & 4.4 & & 4.6 & 4.7 & 4.8 & 4.9 & 4.10 & 4.11 & 4.12 & 4.13 & 4.14 & 4.15 & 4.16 & 4.17 & 4.18 & 4.19 & 4.20 & 1 \\
\hline & 90 & & 4.2 & 4.3 & 4.4 & & 4.6 & 4.7 & 4.8 & 4.9 & 4.10 & 4.11 & 4.12 & 4.13 & 4.14 & 4.15 & 4.16 & 4.17 & 4.18 & & 4.20 & 1 \\
\hline & 100 & & 4.2 & 4.3 & 4.4 & & & 4.7 & 4.8 & 4.9 & 4.10 & 4.11 & 4.12 & 4.13 & 4.14 & 4.15 & 4.16 & 4.17 & 4.18 & & & 1 \\
\hline \multirow{4}{*}[M_{2}+\mathrm{H}]{$^{+}$and/or $\left[M_{2}+\mathrm{Na}\right]^{+}$} & 70 & & & & 4.4 & 4.5 & & & & & & 4.11 & & & 4.14 & 4.15 & 4.16 & & & & 4.20 & \\
\hline & 80 & & & & 4.4 & & & & 4.8 & 4.9 & & 4.11 & & & 4.14 & 4.15 & 4.16 & & & & 4.20 & \\
\hline & 90 & & & & & 4.5 & & & 4.8 & 4.9 & & 4.11 & & & 4.14 & 4.15 & 4.16 & & & 4.19 & 4.20 & \\
\hline & 100 & & & & 4.4 & 4.5 & & & 4.8 & 4.9 & & 4.11 & & & 4.14 & 4.15 & 4.16 & & 4.18 & 4.19 & 4.20 & \\
\hline \multirow[t]{4}{*}[M_{3}+\mathrm{H}]{$^{+}$} & 70 & & & & & & & & & & & & & & & & & & & & & \\
\hline & 80 & & & & & & & & & & & & & & & & & & & & & \\
\hline & 90 & & & & & & & & & & & & & & & & & & & 4.19 & & \\
\hline & 100 & & & & & & & & & & & & & & & & & & & 4.19 & & \\
\hline \multirow{4}{*}{$\begin{array}{l}{[5+\mathrm{H}]^{+}, \text {quasi-molecular ion }} \\
\text { of MAQ }(m / z=175)\end{array}$} & 70 & 4.1 & 4.2 & 4.3 & 4.4 & 4.5 & & & 4.8 & 4.9 & & 4.11 & 4.12 & 4.13 & 4.14 & 4.15 & 4.16 & 4.17 & 4.18 & 4.19 & 4.20 & 1 \\
\hline & 80 & 4.1 & 4.2 & 4.3 & 4.4 & 4.5 & & & 4.8 & 4.9 & & 4.11 & 4.12 & 4.13 & 4.14 & 4.15 & 4.16 & 4.17 & 4.18 & 4.19 & 4.20 & 1 \\
\hline & 90 & & 4.2 & 4.3 & 4.4 & 4.5 & & & 4.8 & 4.9 & & 4.11 & 4.12 & 4.13 & 4.14 & 4.15 & 4.16 & 4.17 & 4.18 & & & 1 \\
\hline & 100 & & 4.2 & 4.3 & 4.4 & & & & 4.8 & 4.9 & & 4.11 & 4.12 & 4.13 & 4.14 & 4.15 & 4.16 & 4.17 & 4.18 & & & 1 \\
\hline \multirow{4}{*}{$\begin{array}{l}{[\mathrm{DHQ}+\mathrm{H}]^{+}, \text {quasi-molecular ion of }} \\
7,8 \text {-dihydroquinoline }(\mathrm{m} / \mathrm{z}=132)\end{array}$} & 70 & 4.1 & 4.2 & 4.3 & 4.4 & 4.5 & & & & & & & & & & & 4.16 & & & 4.19 & & 1 \\
\hline & 80 & 4.1 & 4.2 & 4.3 & 4.4 & 4.5 & & & 4.8 & & & 4.11 & 4.12 & 4.13 & & & 4.16 & & & 4.19 & & 1 \\
\hline & 90 & 4.1 & 4.2 & 4.3 & & 4.5 & & 4.7 & 4.8 & 4.9 & & 4.11 & 4.12 & 4.13 & & 4.15 & 4.16 & & & 4.19 & & 1 \\
\hline & 100 & 4.1 & 4.2 & 4.3 & & 4.5 & & 4.7 & 4.8 & 4.9 & & 4.11 & 4.12 & 4.13 & & 4.15 & 4.16 & & & 4.19 & & 1 \\
\hline
\end{tabular}


same procedure and were synthesized in goods yields from the corresponding $\alpha$-aminoamides (3, Scheme 1$)$ by refluxing with an excess of the appropriate ketone in methanol, in the presence of triethylamine and molecular sieves. The structures of the new compounds were confirmed by ${ }^{1} \mathrm{H}$ and ${ }^{13} \mathrm{C} \mathrm{NMR}$, and also by HRMS using the MALDI-TOF technique ( $c f$. Supporting Information).

\section{2. $E S I-M S^{n}$ analysis}

ESI-MS $^{n}$ studies on compounds 4.1-4.20 (Table 1) were achieved using a Finnigan Surveyor LCQ DECA XP MAX quadrupole ion trap mass spectrometer, utilizing electrospray ionization (ESI). Methanolic solutions of the compounds, containing $0.1 \%$ acetic acid, were infused into the ESI probe at a rate of $3 \mu \mathrm{L} \mathrm{min}^{-1}$. Inclusion of methanol to prepare samples was necessary to obtain good electrospray behavior [26]. In the ESI source, nitrogen sheath gas flow was maintained at $20 \mathrm{psi}$, the capillary temperature was set to $275^{\circ} \mathrm{C}$ and the spray voltage was set to $5 \mathrm{kV}$. Capillary voltage was of $15 \mathrm{~V}$ and tube lens voltage was of $30 \mathrm{~V}$. All spectra were obtained in positive mode and data were collected and analyzed by using the Xcalibur software developed by ThermoFinnigan. To induce sample fragmentation, two processes were used: collision-induced dissociation (CID) in the nozzle-skimmer region and tandem-MS. In the first process, fragmentation is induced by colliding sample ions with the background gas in the intermediate-pressure region of the ESI interface. This region is also called "nozzle- skimmer" and gas pressure is about $10^{-1}$ mbar. Increasing the voltage between the nozzle and the skimmer $\left(V_{\mathrm{s}} \mathrm{CID}\right)$ increases the kinetic energy of the ions passing through this region. This raises the energy of collision between the ions and background gas, eventually causing fragmentation [43].

Tandem-MS or MS/MS occurs at the high vacuum region of the mass analyzer; the ion of interest is isolated within the ion trap by ejecting all other ions out of the trap. Then, this ion is accelerated, by applying a high-frequency AC voltage, and collides with a collision gas. The fragmentation ions generated are then detected by a mass scan [43]. The collision energy needed to achieve optimum fragmentation efficiency has been shown to follow a linear correlation with $\mathrm{m} / \mathrm{z}$. The normalized collision energy (NCE) principle automatically compensates for this mass dependency [44].

Three types of fragmentation experiments were conducted. The first was carried out on the nozzle-skimmer region where the $V_{\mathrm{s}}$ CID parameter was varied between 70 and $100 \mathrm{~V}$. The evaluation of the influence of the voltage in-source on the fragmentation patterns provides a means to distinguish stable adducts from unstable species.

The second experiment was done by tandem-MS and was characterized by varying the NCE levels at 10, 20, 30 or $40 \%$. This was done to establish the optimal NCE value that would allow, through $\mathrm{MS}^{2}$ spectra, to analyze the structural stability of the sample, as this parameter has been used to predict drug metabolites at given NCE values as recommended by the MS manufacturer $(25$ or $30 \%)[32,44]$.<smiles>[R]C1NC([R])([R])N(CCCC2CNCCC2[Z]([H])([H])[H])C1=O</smiles><smiles>[R]C1NC([R])([R])N(CCCC=C)C1=O</smiles>

Scheme 2. Main MS/MS fragmentation of compounds 4 at normalized collision energies of 30 and $40 \%$. 
The third experiment was also done by tandem-MS at a fixed NCE value of $30 \%$, for subsequent $\mathrm{MS}^{n}$ analysis of the main fragment generated on the previous $\mathrm{MS}^{n-1}$ fragmentation $(n=3,4) . \mathrm{MS}^{2}$ fragmentation was done on the quasi-molecular ion $\left([M+\mathrm{H}]^{+}\right)$observed in the corresponding full-MS spectrum. This was not necessarily the base peak, as imidazolidin-4-ones 4 were quite prone to form sodium adducts $\left([M+\mathrm{Na}]^{+}\right.$species $)$ that were frequently the base peaks in full-MS spectra.

\section{Results and discussion}

\subsection{Experiments in the nozzle-skimmer region}

Spectra were obtained at four different voltages, 70, 80, 90 and $100 \mathrm{~V}$. These can be regarded as high values $(100 \mathrm{~V}$ is the maximum reached by the spectrometer) that were deliberately chosen to test compound resistance against bond disruption under highly fragmentative conditions. Results compiled in Table 2 demonstrate that compounds $\mathbf{4}$ were mainly detected as $[M+\mathrm{H}]^{+}$and/or $[M+\mathrm{Na}]^{+}$ions. The two major occurring fragmentations led to observation of peaks at $\mathrm{m} / \mathrm{z} 175$ and $\mathrm{m} / \mathrm{z}$ 132 that were respectively associated to the quasi-molecular
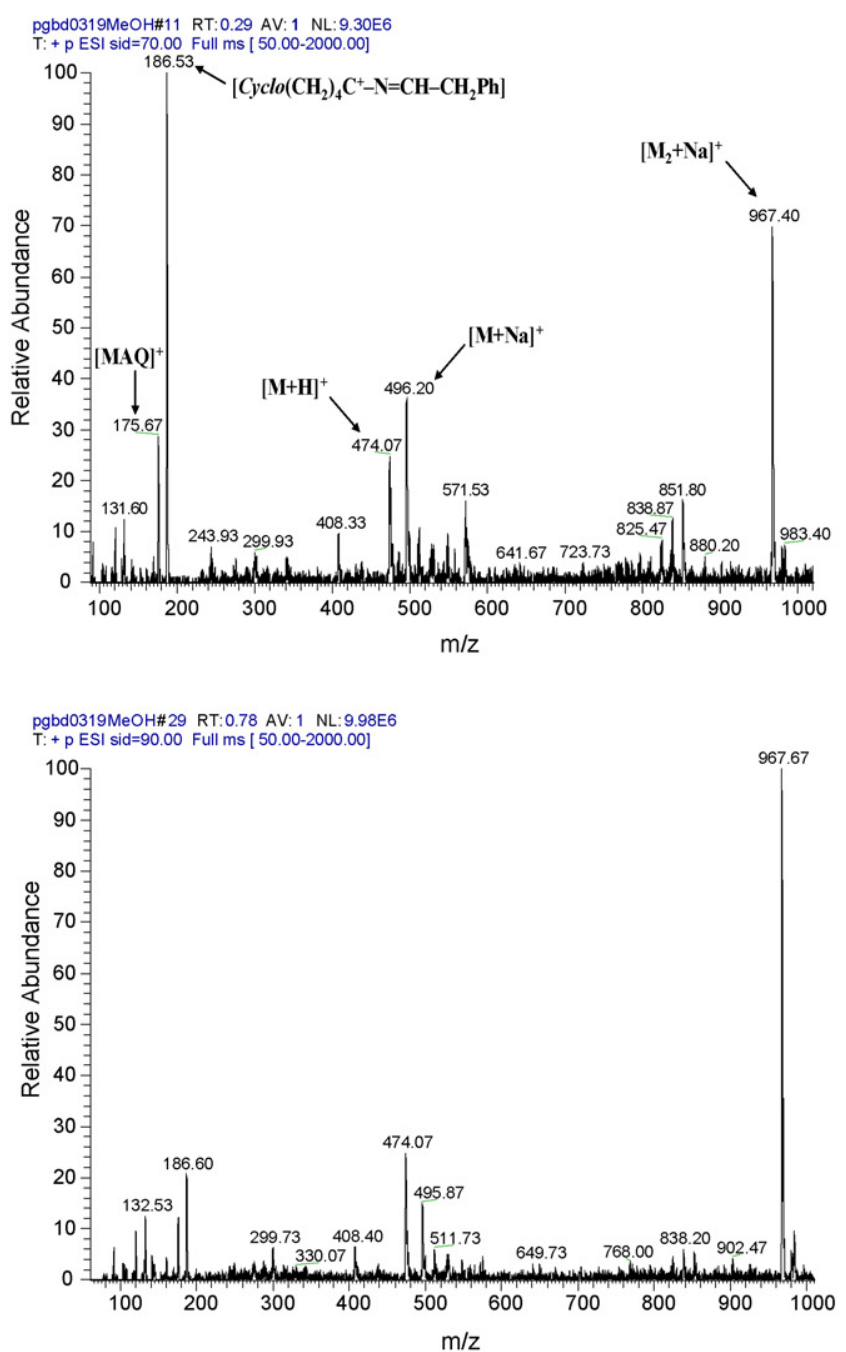

ions $\left([M+\mathrm{H}]^{+}\right)$of 6-methoxy-8-aminoquinoline (MAQ, 5 on Scheme 2) and of, probably, 7,8-dihydroquinoline (DHQ, $\mathrm{MW}=131 \mathrm{~g} \mathrm{~mol}^{-1}$ ) that can be generated from any of compounds 4. DHQ has also been previously found as the major product of $\mathrm{MS}^{2}$ fragmentation of nicotine [34].

Some of the imidazolidin-4-ones, such as $\mathbf{4 . 1}$ and 4.5 gave rise to complex spectra, presenting a high number of peaks and not showing either the imidazolidin-4-one quasi-molecular ion $[M+\mathrm{H}]^{+}$or its sodium adduct $[M+\mathrm{Na}]^{+}$at any of the four voltages employed, which was interpreted as an outcome of their higher instability at the analysis conditions employed.

The above situation was exceptional, as the majority of compounds 4 generated relatively clean spectra with no increase on fragmentative phenomena at higher voltages. An example is that of compound $\mathbf{4 . 2 0}$ whose spectrum is mainly composed by peaks due to the following ions: $[M+\mathrm{H}]^{+},[M+\mathrm{Na}]^{+}$, $\left[M_{2}+\mathrm{Na}\right]^{+}$and by a peak at $m / z=186$ due to fragment cyclo $\left[\left(\mathrm{CH}_{2}\right)_{4} \mathrm{C}^{+}\right]-\mathrm{N}=\mathrm{CH}-\mathrm{CH}_{2} \mathrm{Ph}$ (see Section 3.3). Fig. 1 displays the spectra obtained for $\mathbf{4 . 2 0}$ at the four different voltages used, showing that increasing the potential provokes a decrease on peak intensity at $m / z=186$, but favors the in-source forma-
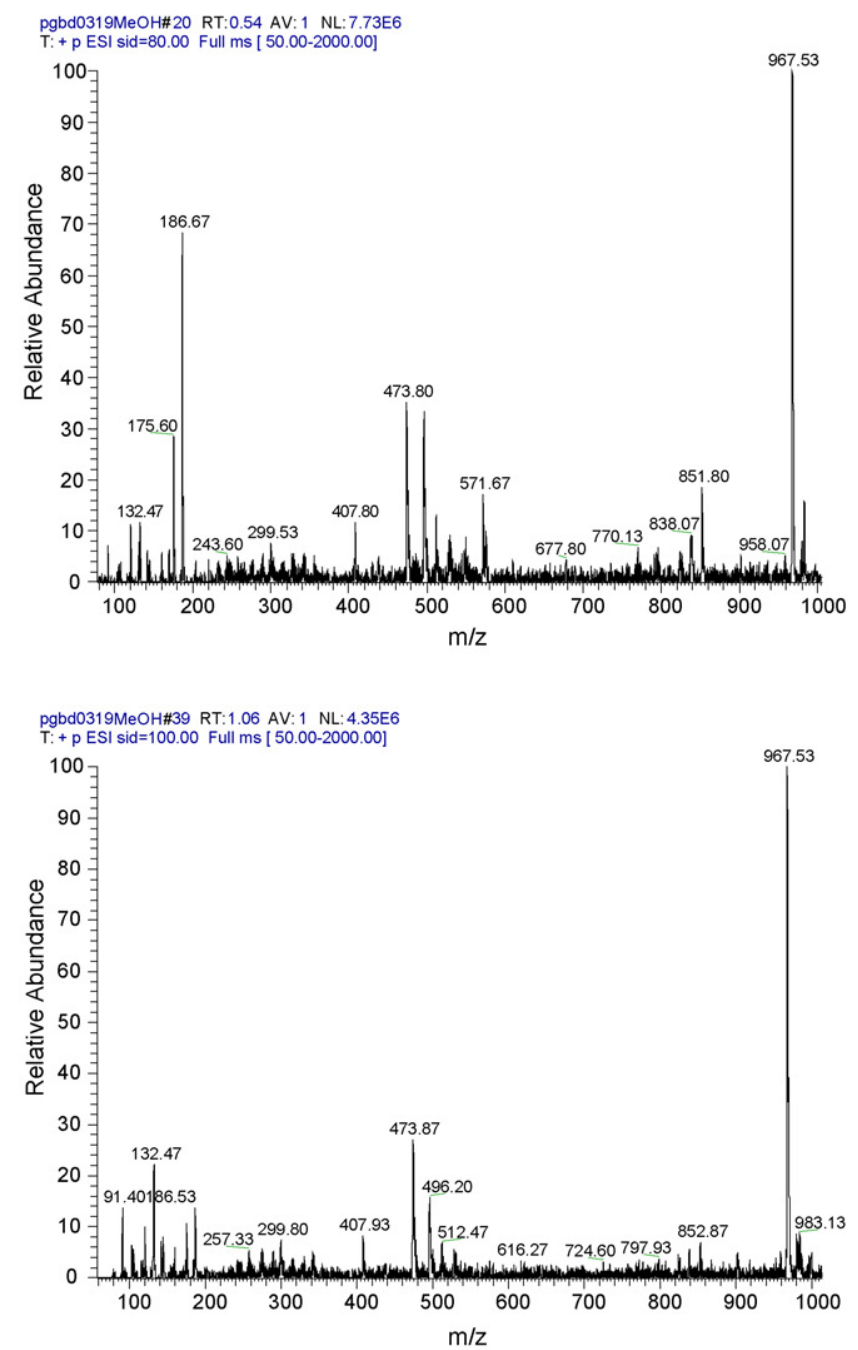

Fig. 1. Fragmentation spectra for compound $\mathbf{4 . 2 0}$ on the skimmer-CID region at 70, 80, 90 and $100 \mathrm{~V}$. 
Table 3

$\mathrm{MS}^{2}$ data obtained at varying normalized collision energies

\begin{tabular}{|c|c|c|c|c|c|c|}
\hline \multirow{3}{*}{ 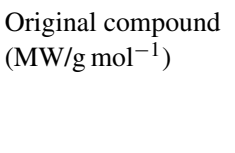 } & \multicolumn{4}{|c|}{ Base-peak observed $(\mathrm{m} / \mathrm{z})$} & \multirow{3}{*}{$\begin{array}{l}\text { Relative abundance of the } \\
\text { original species at NCE } 30 \%\end{array}$} & \multirow{3}{*}{$\begin{array}{l}\text { Relative abundance of } \\
\text { MAQ (5) at NCE } 30 \%^{\mathrm{a}}\end{array}$} \\
\hline & \multicolumn{4}{|c|}{ Normalized collision energy (\%) for MS/MS } & & \\
\hline & 10 & 20 & 30 & 40 & & \\
\hline $4.1(356.46)$ & 357.19 & 357.19 & 183.15 & 183.15 & 23.86 & 7.10 \\
\hline $\mathbf{4 . 2}(370.49)$ & 371.20 & 371.20 & 197.13 & 197.13 & 11.83 & 10.52 \\
\hline $\mathbf{4 . 3}(398.45)$ & 399.20 & 399.20 & 225.13 & 225.13 & 15.03 & 11.31 \\
\hline $4.4(446.58)$ & 447.12 & 447.18 & 273.15 & 273.15 & 24.22 & 3.83 \\
\hline $4.5(412.57)$ & 413.27 & 413.33 & 239.20 & 239.20 & 30.23 & 6.34 \\
\hline 4.6(412.57) & 413.27 & 413.27 & 239.20 & 239.20 & 27.93 & 7.44 \\
\hline $4.7(424.58)$ & 425.29 & 425.29 & 251.18 & 251.18 & 27.89 & 4.31 \\
\hline $4.8(438.61)$ & 439.27 & 439.27 & 265.16 & 265.16 & 11.63 & 7.48 \\
\hline $\mathbf{4 . 9}(452.63)$ & 453.30 & 453.30 & 279.20 & 279.20 & 18.00 & 12.28 \\
\hline $\mathbf{4 . 1 0}(452.63)$ & 453.20 & 453.20 & 279.27 & 279.13 & 31.80 & 8.12 \\
\hline $4.11(410.55)$ & 411.20 & 411.20 & 237.33 & 237.33 & 23.28 & 7.12 \\
\hline $4.12(424.58)$ & 425.22 & 425.22 & 251.25 & 251.25 & 18.36 & 8.62 \\
\hline $\mathbf{4 . 1 3}(424.58)$ & 425.22 & 425.22 & 251.25 & 251.18 & 28.98 & 10.80 \\
\hline $4.14(466.66)$ & 467.27 & 467.27 & 293.27 & 293.27 & 23.80 & 14.49 \\
\hline $4.15(466.66)$ & 467.33 & 467.33 & 293.33 & 293.20 & 44.06 & 9.26 \\
\hline $4.16(396.53)$ & 398.20 & 398.20 & 224.27 & 224.27 & 23.50 & 13.75 \\
\hline $4.17(452.63)$ & 453.24 & 453.24 & 279.27 & 279.20 & 33.06 & 6.28 \\
\hline 4.18(452.63) & 453.27 & 453.33 & 279.27 & 279.20 & 22.74 & 8.31 \\
\hline $\mathbf{4 . 1 9}(396.53)$ & 397.20 & 397.20 & 223.20 & 223.13 & 19.54 & 4.91 \\
\hline $\mathbf{4 . 2 0}(472.62)$ & 473.20 & 473.20 & 299.27 & 299.20 & 18.27 & 1.63 \\
\hline $\mathbf{1}((259.35)$ & 260.07 & 260.00 & 243.24 & 243.17 & 0.00 & 34.86 \\
\hline $\mathbf{3 . 2}(330.42)$ & 331.23 & 331.23 & 157.19 & 157.06 & 21.37 & 57.59 \\
\hline
\end{tabular}

${ }^{\text {a }}$ Fragment common to all compounds studied, with $m / z\left([M+\mathrm{H}]^{+}\right)=175$. 
tion of the $\left[M_{2}+\mathrm{Na}\right]^{+}$adduct. Peak intensity for ions $[M+\mathrm{H}]^{+}$ and $[M+\mathrm{Na}]^{+}$are similar, but there is a slight inversion on relative intensity when the potential is increased. The fragmentation behavior of compound $\mathbf{4 . 2 0}$ under these conditions suggests that its structure is quite stable. Interestingly, this compound has been previously characterized as highly stable in human plasma at physiological $\mathrm{pH}$ and temperature, where it remains intact after $72 \mathrm{~h}$ of incubation $[41,42]$.

Another example of remarkable stability under the conditions of the ESI-MS analysis refers to compound 4.7, whose fragmentation behavior in-source is slightly different from that of 4.20. In the case of 4.7, voltage increase favors the formation of the $[M+\mathrm{Na}]^{+}$ion, whereas the number and type of fragments remain unchanged (not shown). In fact, all imidazolidin-4-ones derived from the amino acid valine were seen to be stable towards in-source fragmentation, as further illustrated by the behavior of compound $\mathbf{4 . 1 0}$ that does not even originate the fragments at $m / z=175$ and 132 , currently observed for the generality of compounds 4 (Table 2).

Finally, it must be outlined that acetone-derived imidazolidin4-ones (4.1-4.6), especially smaller ones, were clearly more "fragmentable" than those derived from cyclic ketones. Again, it is interesting to notice that a similar stability pattern was observed for compounds $\mathbf{4}$ under totally different conditions, namely, towards hydrolysis at physiological $\mathrm{pH}$ and temperature $[41,42]$.

(A)

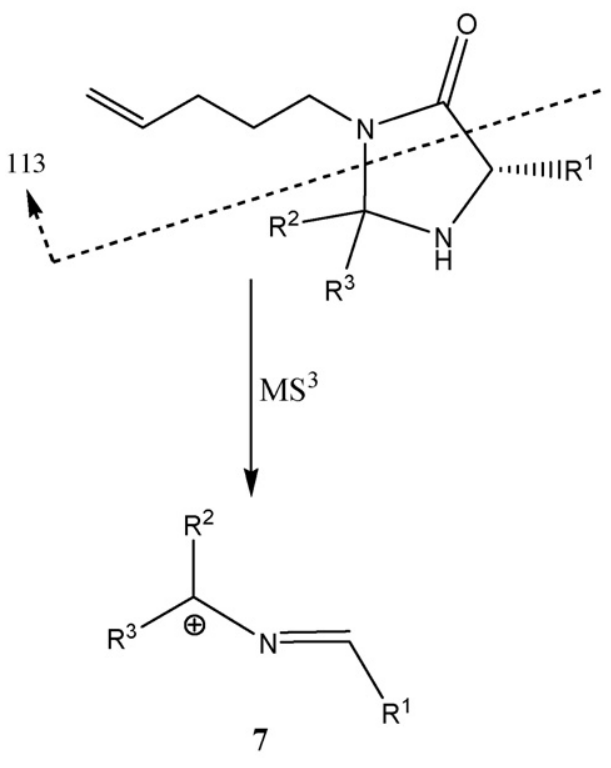

Both the parent drug (PQ, 1) and the linear $\alpha$-aminoamide precursor of Ala-derived imidazolidin-4-ones 4.2, 4.12, 4.13, 4.19, compound 3.2 (Table 1), were subject of an identical study in the nozzle-skimmer region. We could observe that the insource behavior of both $\mathbf{1}$ and $\mathbf{3 . 2}$ were quite different from those of compounds $\mathbf{4}$, in the sense that both compounds gave rise to much "dirtier" spectra and to significant signal carry-over between analyses (data not shown). This was interpreted, respectively, as due to higher compound instability in the course of the MS analysis and to the fact that both compounds have a terminal primary amino group that can strongly attach to the fused silica capillary. This latter fact turned comparisons between linear and cyclic compounds out of significance.

\subsection{ESI-MS $S^{2}$ analysis at varying NCE values}

This set of experiments was aimed at the determination of the influence of the normalized collision energy on the mechanism and extension of fragmentation of compounds 4.1-4.20. Compounds 1 and $\mathbf{3 . 2}$ were included for comparison.

Many reports in the literature have been devoted to characterization of different compounds by tandem-MS, with particular attention to the conditions of collision, i.e., NCE values [45-49]. In the majority of those reports, $25 \%$ was used as the standard value for NCE in drug fragmentation studies. In our case, we have raised the NCE up to $40 \%$ to fully characterize the behav-

(B)
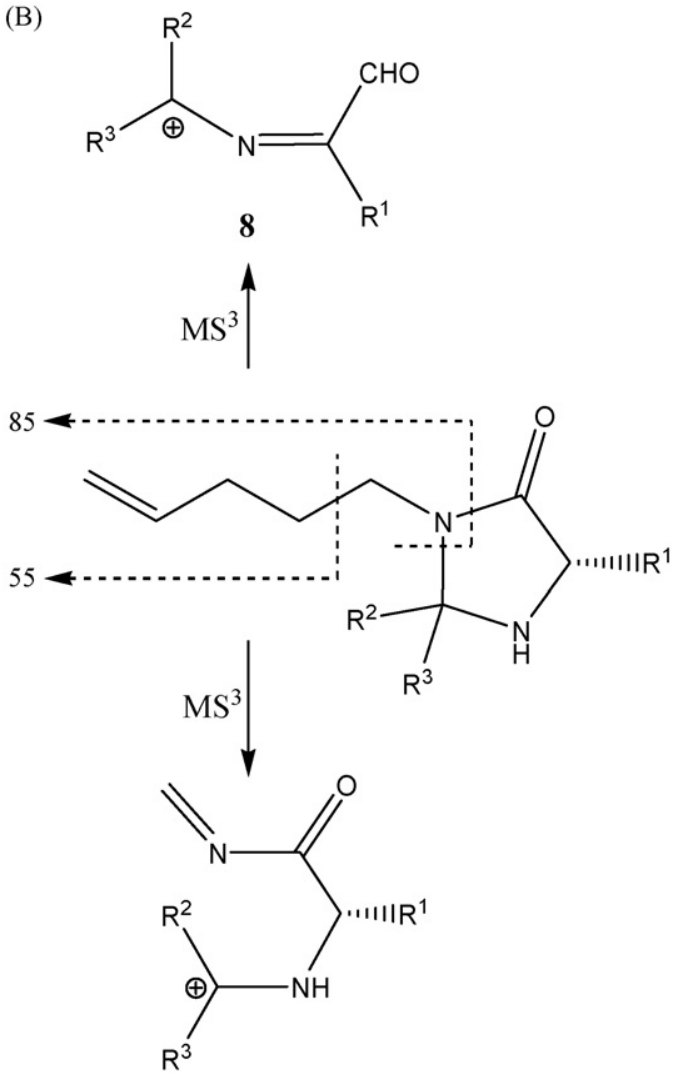

9

Scheme 3. Fragmentations of compounds 4 in the $\mathrm{MS}^{3}$ mode at 30\% NCE: (A) main fragmentation pathway; (B) additional relevant fragmentations on structures derived from 4.1, 4.2, 4.13 and 4.16. 
ior of imidazolidin-4-ones 4. As shown by data in Table 3, at NCE values of 10 and $20 \%$, the base-peak was still the quasimolecular ion $[M+\mathrm{H}]^{+}$, whereas at 30 and $40 \%$, the base-peak occurs, for all cases, at $m / z=m / z[M+\mathrm{H}]^{+}-174$. This is due to loss of the 6-methoxy-8-aminoquinoline core (MAQ, 5), as depicted in Scheme 2.

The fragmentation pathway proposed in Scheme 2, involving elimination of a primary amine (MAQ, 5), is corroborated by a previous LC/ESI-MS characterization of primaquine (1) and its major contaminant, quinocide, carried out by Brondz et al. [10]. Other examples where $\mathrm{MS}^{2}$ fragmentation leads to cleavage of a $\mathrm{C}-\mathrm{N}$ bond with amine release are mostly found for tertiary amines, as these have $\mathrm{C}-\mathrm{N}$ bond dissociation energies (BDE) lower than those of their secondary amine counterparts [31]. For instance, the ESI-MS behavior of therapeutically relevant tertiary amines has been described by Smyth

(A)
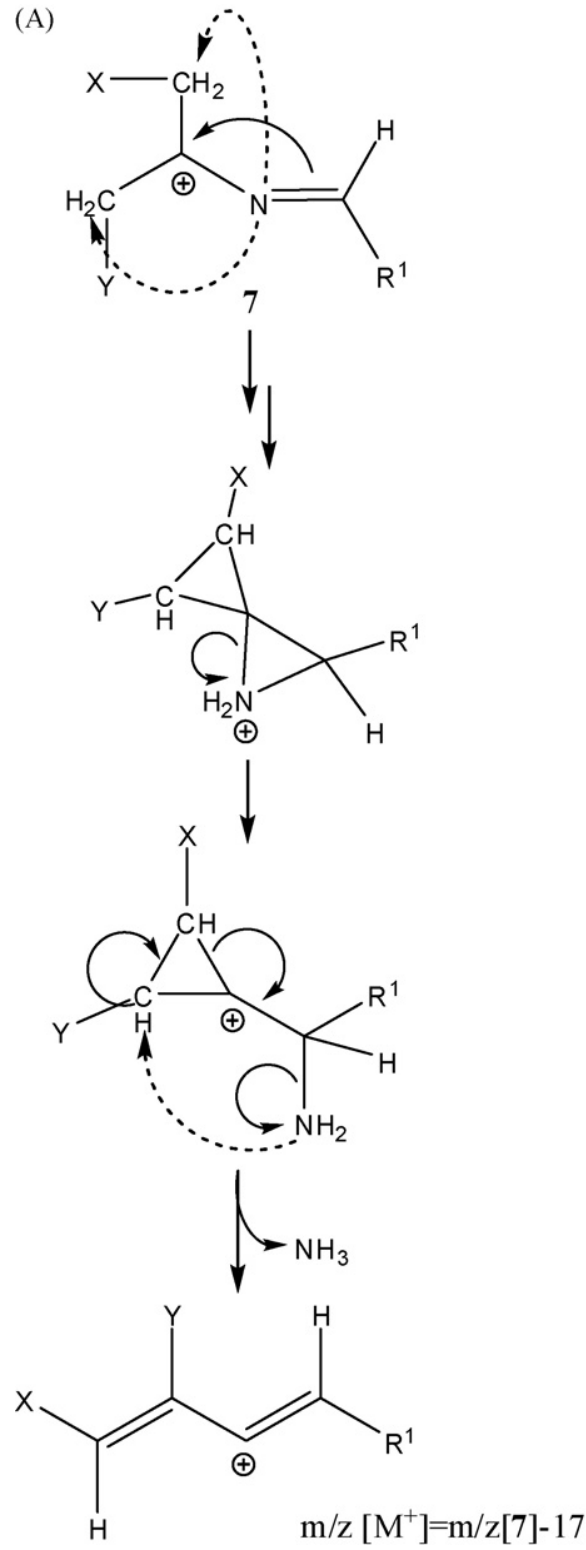

and co-workers to involve fragmentation to smaller amines [34,47], as nicely reviewed in [31]. Amine release is also common in $\mathrm{MS}^{2}$ fragmentations of oligopeptides, though through different pathways, as for instance the $\mathrm{y}_{7}$ fragmentation of the bioactive octapeptide Angiotensin II, corresponding to loss of the N-terminal Asp residue as 3-aminodihydrofuran-2,5-dione. The remaining heptapeptide is thus released, where Arg is the new $\mathrm{N}$-terminal residue, having its $\alpha$-amino group now free [49].

The behavior of compounds 4 at the four different NCE values tested can be illustrated with data obtained for compound $\mathbf{4 . 4}$ as compared to that of the parent drug $(\mathrm{PQ}, \mathbf{1})$. At NCE $=20 \%$, some fragmentation is already observed for $\mathbf{1}\left(\mathrm{MW}, 260 \mathrm{~g} \mathrm{~mol}^{-1}\right.$ ) with fragments at $m / z 243$ and 175 , respectively due to loss of the terminal primary amino group (as ammonia) and of the whole aliphatic chain linked to the 8-amino group yielding MAQ (5).

(B)<smiles>[X]CC1(N=C([R1])C)CCCC1[Y]</smiles>

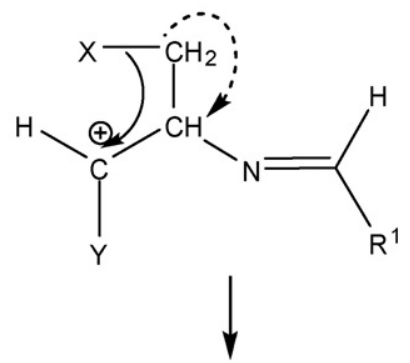<smiles>[R1]C=N[C+]1CCCCCCCCC1([Y])[X]</smiles><smiles>CC1C(C)C1C</smiles>

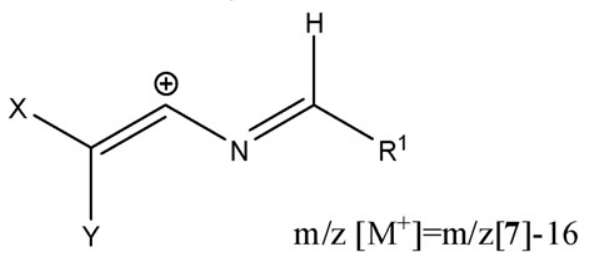

Scheme 4. Hypothetical pathways leading to loss of $\mathrm{NH}_{3}$ (A) or $\mathrm{CH}_{4}$ (B) from species 7 in $\mathrm{MS}^{4}$ analyses $\left[\mathrm{X}=\mathrm{Y}=-\mathrm{H}\right.$ or $\mathrm{X}$ and $\mathrm{Y}=-\left(\mathrm{CH}_{2}\right)_{n}-$ with $n=2,3,4$ or $\mathrm{X}$ and $\left.\mathrm{Y}=-\left(\mathrm{CH}_{2}\right)_{2}-\mathrm{CH}\left(\mathrm{CH}_{3}\right)-\left(\mathrm{CH}_{2}\right)_{2}-\right]$. 

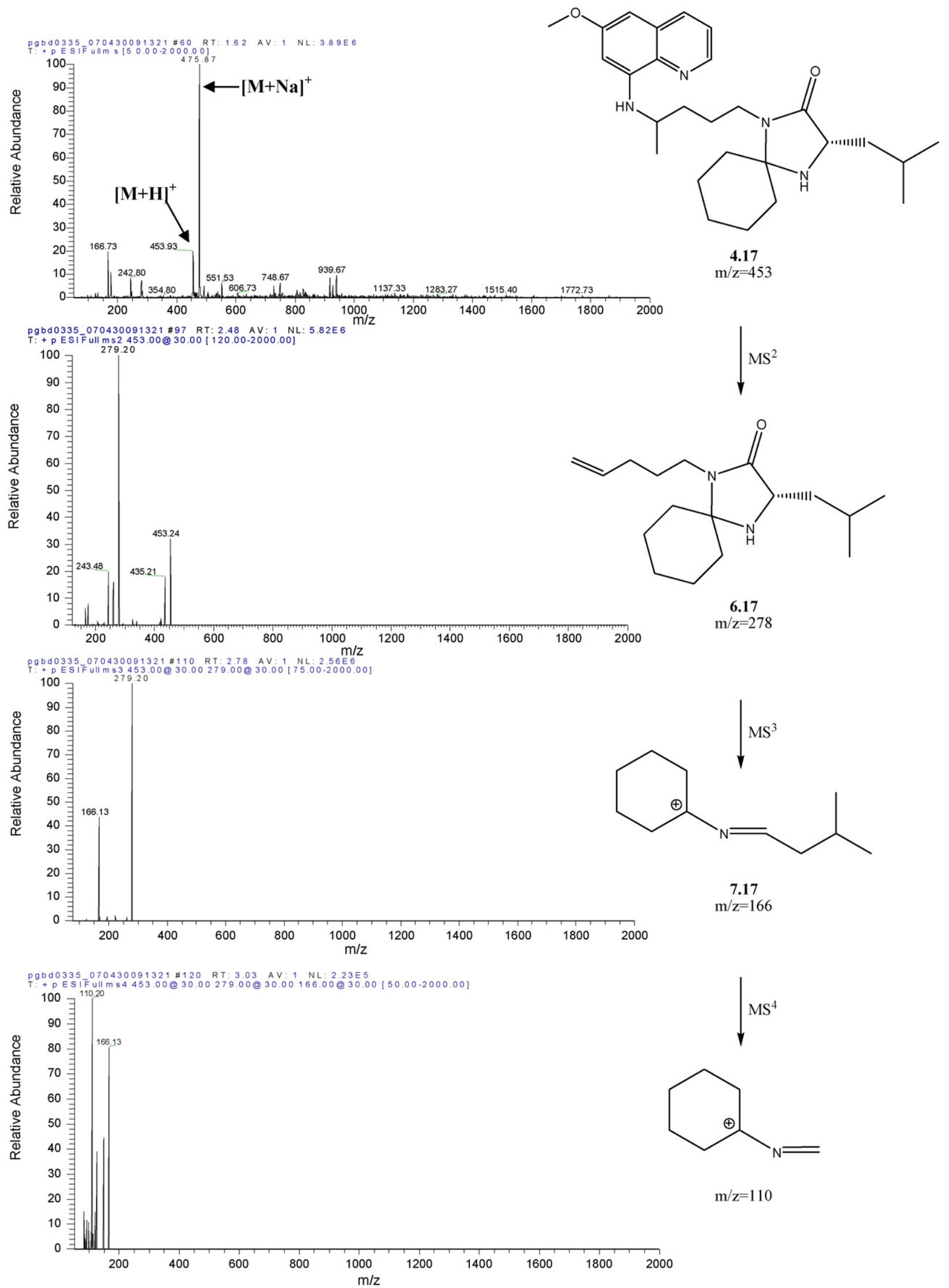

$\mathrm{m} / \mathrm{z}=110$

Fig. 2. $\mathrm{MS}^{n}$ spectra for imidazolidin-4-one 4.17; main fragmentations are shown on the right. 
Increasing NCE to $30 \%$ leads to complete destruction of PQ, whose quasi-molecular ion at $\mathrm{m} / \mathrm{z} 260$ is no longer observable. The behavior of PQ in the course of our experiments is again confirmed previous findings by LC/ESI-MS analysis reported by Brondz et al. [10]. In what concerns compound 4.4, fragmentation (loss of MAQ) is only detected at NCE $\geq 30 \%$. Anyway, as already mentioned in Section 3.1, the different behavior of compounds 1 and 3.2, due to their higher retention by the fused silica capillary as compared to compounds $\mathbf{4}$, led us to consider the relative abundance of the common MAQ fragment (5) at $\mathrm{NCE}=30 \%$ (Table 3) as a more suitable parameter to compare relative stabilities of these compounds. Hence, while the relative abundance of MAQ detected at $\mathrm{NCE}=30 \%$ is seldom higher than $10 \%$ for compounds $\mathbf{4}$, it rises up to $35 \%$ for PQ (1) and to $58 \%$ for 3.2. Once more, the remarkable stability of imidazoldin-4-ones $\mathbf{4}$ is here outlined, as compared to those of their $\alpha$-aminoamide (3) and PQ (1) precursors. Again, this coincides with the distinctive behavior of these compounds under completely different conditions, i.e., hydrolysis in either buffer or plasma at physiological $\mathrm{pH}$ and temperature [41,42].
Other PQ-derived imidazolidin-4-ones were seen to be highly stable in the course of these ESI-MS ${ }^{2}$ experiments, namely PQValC5 (4.7), all three derivatives of 4-methylcyclohexanone (4.10-4.12) and, specially, PQIleC7 (4.15). The main, and practically only, fragmentation of $\mathbf{4 . 7}$ corresponds to loss of MAQ, has happens in all other cases, and relative abundance of the original protonated species $[M+\mathrm{H}]^{+}$is ca. $28 \%$ (Table 3 ) that is clearly lower than that measured for $\mathbf{4 . 1 5}$ (44\%). However, in this latter case, a higher number of fragments can be identified, showing that more fragmentation paths are followed, even though to a very small extent.

Taken together, these observations show that the imidazolidin-4-one ring in compounds $\mathbf{4}$ is remarkably stable, as at NCE values as high as $40 \%$ the main fragmentative phenomenon is the cleavage of the $\mathrm{N}-\mathrm{C}$ bond that links the PQ's 8-amino group and the aliphatic chain, while the pentagonal ring is left intact. Thus, we can affirm that the imidazolidin-4-one ring is highly stable even under harsh fragmentative conditions that lead to bond breaking in other parts of the molecular structure. As previously referred, these

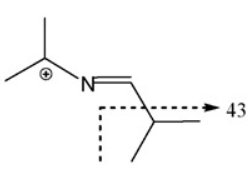

7.3

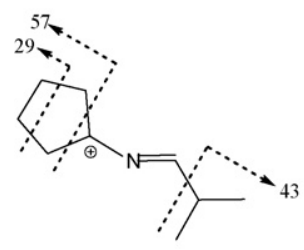

7.7

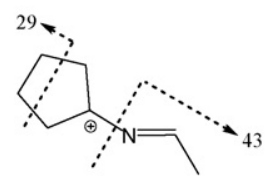

7.19

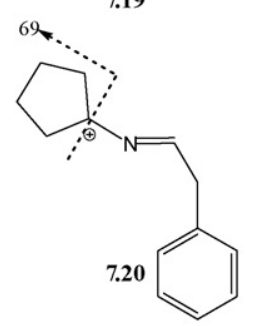

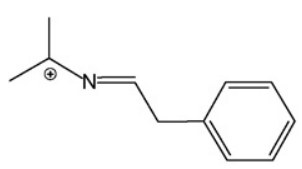

7.4

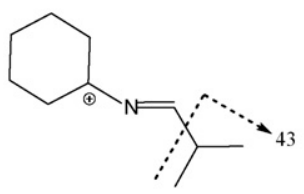

7.8
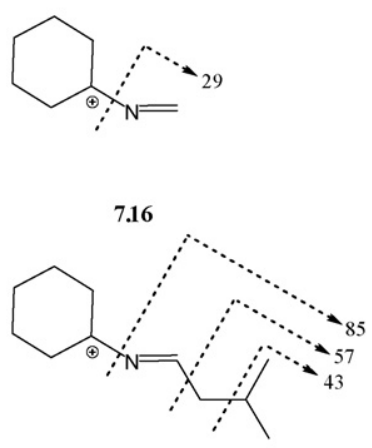

7.17

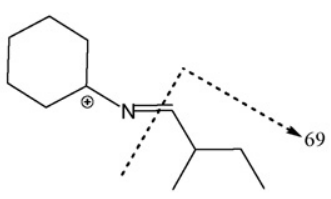

7.18
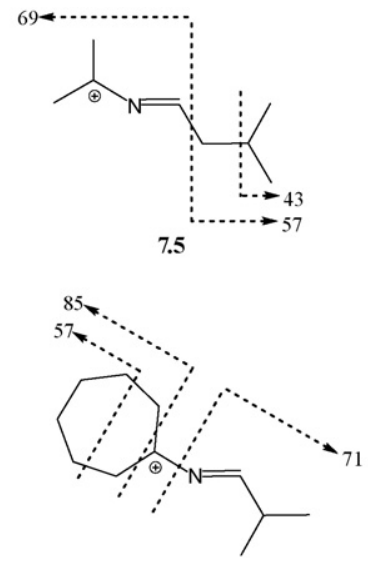

7.9

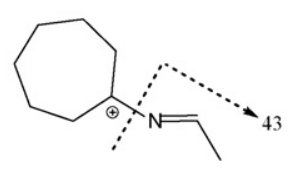

7.13

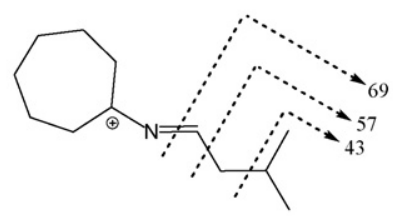

7.14

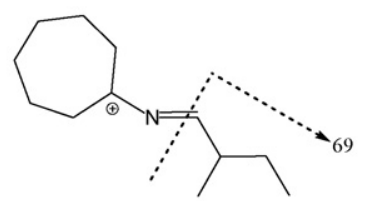

7.15

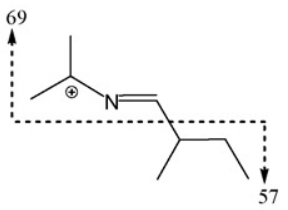

7.6
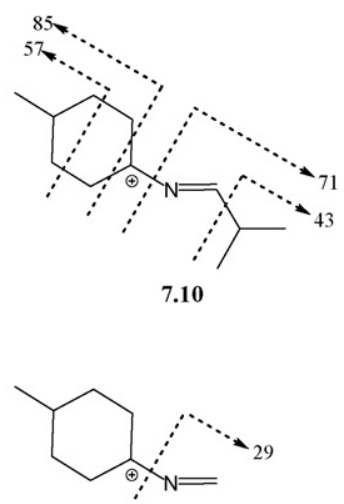

7.11

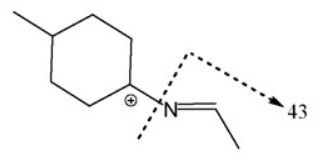

7.12

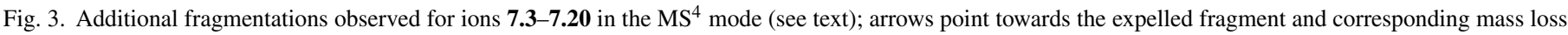
in a.m.u. 

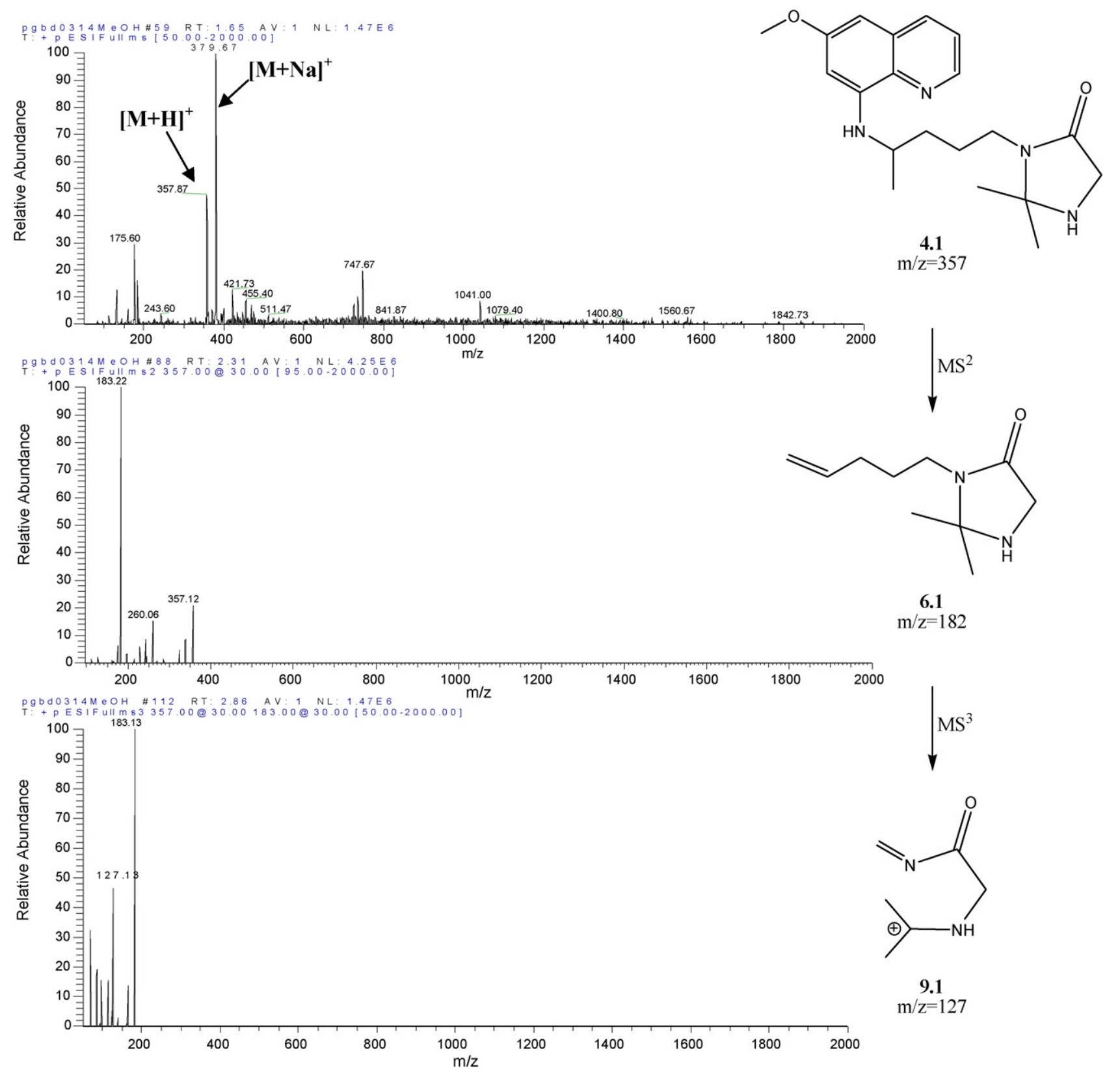

$\mathrm{MS}^{2}$

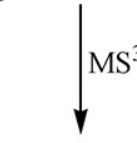

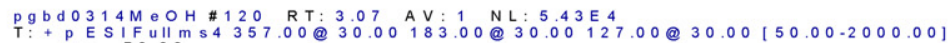

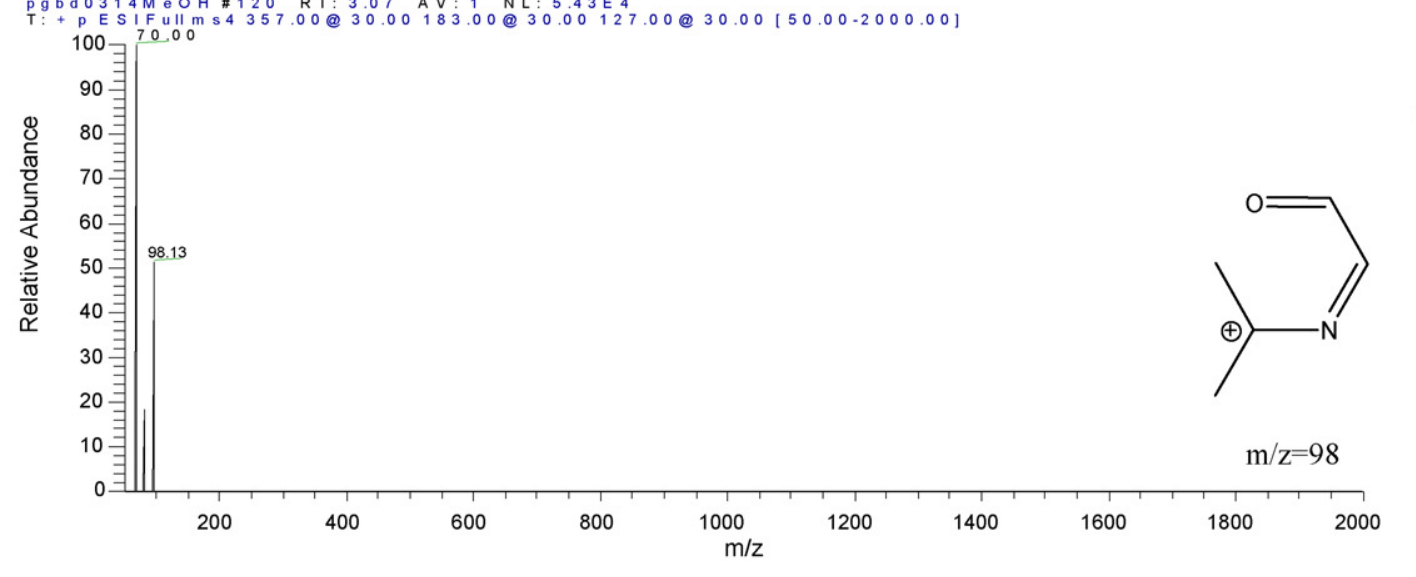

$\mathrm{m} / \mathrm{z}=127$

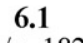

$\begin{aligned} & 6.1 \\ & m / z\end{aligned}=182$

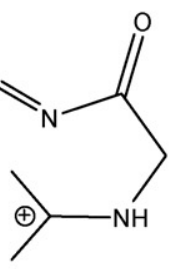

9.1

$\downarrow \mathrm{MS}^{4}$

Fig. 4. $\mathrm{MS}^{n}$ spectra for imidazolidin-4-one 4.1; main fragmentations are shown on the right. 
compounds are also remarkably stable towards hydrolysis under physiological conditions, which may become an advantage in terms of bioavailability, as imidazolidin-4-ones 4 have presented relevant biological activity against rodent malaria [40-42,50].

\section{3. $E S I-M S^{n}$ analysis at $N C E=30 \%$}

As described in Section 3.2, fragmentations occur on compounds 4 only at $30 \%$ and higher NCE values. Thus, to carry out a full study of the fragmentation mechanisms of the PQderived imidazolidin-4-ones, we have fixed the NCE at $30 \%$ and performed an extended $\mathrm{MS}^{n}$ analysis, as detailed in Section 2.2 .

$\mathrm{MS}^{2}$ analysis at NCE $=30 \%$ has been covered in Section 3.2 and will be no further discussed. As already mentioned, the main fragment observed in all $\mathrm{MS}^{2}$ spectra of compounds 4 corresponded to loss of MAQ, yielding structure 6 (Scheme 2) that was selected for $\mathrm{MS}^{3}$ fragmentation. The original species (6) was still observed as the base peak in the $\mathrm{MS}^{3}$ mode, except for compound 4.8, where the base peak was generated by loss of 113 atomic mass units (a.m.u.). In fact, for 16 out of the 20 imidazolidin-4-ones 4 only such fragmentation was significant in the $\mathrm{MS}^{3}$ mode, i.e., loss of 113 a.m.u. was invariably observed. Hence, the most relevant imidazolidin-4-one fragmentation pathway in the $\mathrm{MS}^{3}$ mode corresponds to ring opening with expulsion of the original PQ's aliphatic chain having its terminal amine still linked to the amino acid's carbonyl. This yields ion $\left(\mathrm{R}^{2}\right)\left(\mathrm{R}^{3}\right) \mathrm{C}^{+}-\mathrm{N}=\mathrm{CHR}^{1}(7)$ as the detected species (Scheme 3A).

The only four cases where $\mathrm{MS}^{3}$ fragmentation yielded fragments other than 7 derived from compounds 4.1, 4.2, 4.13 and 4.16, all of them bearing either Ala or Gly as the amino acid and either acetone or cyclohexanone as the ketone moieties. In the case of cyclohexanone-derived compounds (4.13 and 4.16), only one additional fragment was observed due to loss of the original PQ's aliphatic chain retaining its terminal amine, yielding $\left(\mathrm{R}^{2}\right)\left(\mathrm{R}^{3}\right) \mathrm{C}^{+}-\mathrm{N}=\mathrm{CHR}^{1}-\mathrm{CHO}$ as the detected ion $(\mathbf{8}$, Scheme $3 \mathrm{~B})$. This ion was also observed in the $\mathrm{MS}^{3}$ spectra of the acetone-derived compounds (4.1 and 4.2), but these also exhibited one other relevant fragmentation, probably due to loss of 1,3-butadiene from the linear side chain, with formation of the acyclic ion 9 (Scheme 3B). Actually, this was the fragment (9.1: $\mathrm{R}^{1}=\mathrm{H}, \mathrm{R}^{2}=\mathrm{R}^{3}=\mathrm{Me}, m / z=127$ ) with highest relative abundance in the $\mathrm{MS}^{3}$ spectrum of 4.1. It is noteworthy that these additional fragmentations were not observed for other acetoneor cyclohexanone-derived compounds, which again reflects a higher instability for structures containing Ala or Gly under the analysis conditions. Such behavior is once more coincidental with the reactivity of imidazolidin-4-ones $\mathbf{4}$ towards hydrolysis $[41,42]$.

Given the above described, and except for 4.1, all $\mathrm{MS}^{4}$ fragmentations were carried out from the isolated peak due to the $\mathrm{MS}^{3}$-generated ions 7 (Scheme 3), from now on labeled as 7.1-7.20 according to the numbering of their precursor compounds 4. Fragmentation of ion $7.2\left(R^{1}=R^{2}=R^{3}=M e\right.$ in Scheme 2) did not lead to any detectable species probably because these, if any, had $\mathrm{m} / \mathrm{z}$ values lower than 50 a.m.u., which is the lower limit of the spectral window in the instrumentation used. For the remaining cases, a variable number of fragments was detected, depending on the parent species 7. The most common (and often most abundant) species detected in the $\mathrm{MS}^{4}$ mode corresponded to loss of 17 or 16 a.m.u. (depending on the detected species being an $[M+\mathrm{H}]^{+}$or an $M^{+}$ion). Those values are intuitively associated to expulsion of ammonia or methane, respectively. Both these molecules can only be expelled from ions 7 through considerable structural rearrangement, as for instance those depicted in Scheme 4.

Considerable bond breaking and bond making would have to occur, inclusively through cyclic intermediates (Scheme 4A, for $\mathrm{NH}_{3}$ loss) which may appear a bit too farfetched. Loss of a small amine involving formation of a new cyclic species has been also described for $\mathrm{MS}^{2}$-fragmentation of nicotine, but in such case the pathway for methylamine release with concomitant formation of 7,8-dihydroquinoline is considerably simpler than the one illustrated in Scheme 4A [34]. Notwithstanding, the loss of 17 or 16 a.m.u. is the major fragmentation of ions 7 independently of the nature of $\mathrm{R}^{1}, \mathrm{R}^{2}$ and $\mathrm{R}^{3}$, and most of the carbon skeletons of these three substituents must still be present in the final $\mathrm{MS}^{4}$ detected ions, whatever these might be.

Additional $\mathrm{MS}^{4}$-generated fragments were commonly associated to expulsion of part or whole of the amino acid side chain, as illustrated in Fig. 2 for $\mathbf{4 . 1 7}$ and summarized for all compounds in Fig. 3. Species derived from the amino acids Ile (7.6, 7.15, 7.18) and Phe (7.4, 7.20) were those suffering fewer fragmentations in the $\mathrm{MS}^{4}$ mode, with $\mathbf{7 . 4}$ decomposing solely by the loss of 17 (or 16) a.m.u. described in the previous paragraph. Generally, data were compatible with $\mathrm{C}-\mathrm{C}$ bond breaking occurring at either the right or the left side of the $\mathrm{N}=\mathrm{C}$ double bond in structures 7. Exceptions were registered for Ile- and Leu-derived structures 7.14, 7.15, 7.17 and 7.18, where minor fragments in the $\mathrm{MS}^{4}$ spectra were compatible with breaking of the $\mathrm{N}=\mathrm{C}$ bond and departure of the amino acid side chain attached to its $\alpha$-carbon. Fragmentations at the $\mathrm{R}^{2} / \mathrm{R}^{3}$ substituents were observed for some compounds, but never for acetone- or cyclohexanone-derived ions, thus suggesting a higher stability in these structures.

In the particular case of 4.1, its main $\mathrm{MS}^{3}$-generated fragment (9.1, Scheme 3B) was used to carry on with the $\mathrm{MS}^{4}$ analysis. This led to main fragments at $\mathrm{m} / z=98$ and $\mathrm{m} / z=70$, respectively formed upon loss of methanimine (29 a.m.u.) and $N$-methyleneformamide (57 a.m.u.), as depicted in Fig. 4.

\section{Concluding remarks}

ESI-MS $^{n}$ studies on primaquine-derived imidazolidin-4ones, some of which with proven antimalarial activity, were successfully performed. These studies allowed to confirm the remarkable stability of the imidazolidin-4-one ring under the highly fragmentative conditions of experiments in the nozzleskimmer region and to propose fragmentation pathways from $\mathrm{MS}^{2}$ to $\mathrm{MS}^{4}$ analysis at $\mathrm{NCE}=30 \%$.

Despite the conditions and compound degradation pathways being completely different between hydrolysis at physiological 
$\mathrm{pH} / \mathrm{T}$ and ESI-MS ${ }^{n}$ fragmentations, we observed some parallelism of the behavior of some of the title compounds both in the nozzle-skimmer region and in ESI-MS ${ }^{2}$ analyses, with their previously reported reactivity in both isotonic buffer and human plasma. It would be interesting to determine the reactivity of the entire family of compounds $\mathbf{4}$ towards hydrolysis and to compare data thus obtained with results from these ESI-MS ${ }^{n}$ studies. The finding of a correlation, though unlikely, would be remarkable and have important implications in drug analysis and development.

The ESI-MS ${ }^{n}$ characterization of this family of 8-aminoquinolinic imidazolidin-4-ones showed a common behavioral pattern, where $\mathrm{MS}^{2}$ fragmentation invariably led to detachment of the aromatic heterocyclic core of primaquine, 6-methoxy-8-aminoquinoline, leaving the imidazolidin-4-one cycle untouched. This only suffered fragmentation in the course of further analyses in the $\mathrm{MS}^{3}$ and $\mathrm{MS}^{4}$ modes, where main fragmentation types were again common to most compounds.

To the best of our knowledge, this is the first report on studies of this nature centered on structures such as those of the title compounds and will hopefully serve as a guide for future research focused on molecules bearing similar structural motifs.

\section{Acknowledgments}

NV thanks Fundação para a Ciência e a Tecnologia (FCT, Portugal) for Ph.D. grant SFRH/BD/17754/2004. PG and RM thank FCT for financial support to CIQUP and CECF, respectively. The authors are thankful to Ms. Zélia Azevedo for technical support and are also greatly indebted to Dr. Eliandre de Oliveira (University of Barcelona) for HRMS analyses of the new imidazolidin-4-ones 4.

\section{Appendix A. Supplementary data}

Supplementary data associated with this article can be found, in the online version, at doi:10.1016/j.ijms.2007.12.006.

\section{References}

[1] V.K. Dua, S.N. Sinha, V.P. Sharma, J. Chromatogr. B 708 (1998) 316.

[2] A.K. Dwivedi, S.S. Singh, J. Pharm. Biomed. Anal. 33 (2003) 851.

[3] J. Lal, N. Mehrotra, C.R. Gupta, J. Pharm. Biomed. Anal. 32 (2003) 141.

[4] S.N. Sinha, V.K. Dua, Int. J. Mass Spectrom. 232 (2004) 151

[5] R. Bortocan, P.S. Bonato, Electrophoresis 25 (2004) 2848.

[6] (a) N. Leroux, M. Goethals, T. Zeegers-Huyskens, Vib. Spectrosc. 9 (1995) 235;

(b) F. Zsila, G. Gedeon, Biochem. Biophys. Res. Commun. 346 (2006) 1267.

[7] M.A. La-Scalea, C.M.S. Menezes, G.C. Matsutami, M.C. Polli, S.H.P. Serrano, E.I. Ferreira, Electrochim. Acta 51 (2006) 5103.

[8] I. Brondz, D. Ekeberg, D.S. Bell, A.R. Annino, J.A. Hustad, R. Svendsen, V. Vlachos, P. Oakley, G.J. Langley, T. Mohini, C.G. Amaury, F. Mikhalitsyn, J. Pharm. Biomed. Anal. 43 (2007) 937.

[9] B. Avula, L.M. Tripathi, S.I. Khan, B.L. Tekwani, D. Nanayakkara, W. Gul, M.A. ElSolhly, I.A. Khan, Chromatographia 64 (2006) 429

[10] I. Brondz, D. Mantzilas, U. Klein, D. Ekeberg, E. Hvattum, M.N. Lebedeva, F.S. Mikhailitsyn, G.D. Souleimanov, J. Roe, J. Chromatogr. B 800 (2004) 211.
[11] V.G. Dongre, P.P. Karmuse, M.M. Nimbalkar, D. Singh, A. Kumar, J. Pharm. Biomed. Anal. 39 (2005) 111.

[12] (a) M. Yamashita, J.B. Fenn, J. Phys. Chem. 88 (1984) 4671; (b) M. Yamashita, J.B. Fenn, J. Phys. Chem. 88 (1984) 4451.

[13] R.B. Cole, J. Mass Spectrom. 35 (2000) 763.

[14] G.J.V. Berkel, J. Mass Spectrom. 35 (2000) 773.

[15] M.H. Amad, N.B. Cech, G.S. Jackson, C.G. Enke, J. Mass Spectrom. 35 (2000) 784.

[16] M. Gamero-Castano, J.F. Mora, J. Mass Spectrom. 35 (2000) 790.

[17] P. Kebarle, J. Mass Spectrom. 35 (2000) 804.

[18] N.E. Es-Safi, L. Kerhoas, J. Einhorn, P.H. Ducrot, Int. J. Mass Spectrom. 247 (2005) 93.

[19] M. Holcapek, K. Volná, D. Vanerková, Dyes Pigments 75 (2007) 156.

[20] G.V.Poelhsitz, A.L. Bogado, G.D. Souza, E. Rodrigues-Filho, A.A. Batista, M.P. Araújo, Inorg. Chem. Commun. 10 (2007) 133.

[21] R.D. Smith, J.A. Loo, C.G. Edmonds, C.J. Barinaga, H.R. Udseth, Anal. Chem. 62 (1990) 882.

[22] W.J. Griffiths, A.P. Jonsson, S. Lui, D.K. Rai, Y. Wang, Biochem. J. 355 (2001) 545.

[23] Y. Ye, L.F. Cao, M.Y. Niu, X.C. Liao, Y.F. Zhao, Int. J. Mass Spectrom. 253 (2006) 141.

[24] Q.L. Zeng, W.Z. Chen, Y.F. Zhao, Int. J. Mass. Spectrom. 262 (2007) 161.

[25] H. Yin, A. Chacon, N.A. Porter, D.S. Masterson, J. Am. Soc. Mass Spectrom. 18 (2007) 807.

[26] K.X. Wan, T. Shibue, M.L. Gross, J. Am. Chem. Soc. 122 (2000) 300.

[27] S. McClean, R.C. Robinson, C. Shaw, W.F. Smyth, Rapid Commun. Mass Spectrom. 16 (2002) 346.

[28] Z. Tozuka, H. Kaneko, T. Shiraga, Y. Mitani, A. Kawamura, A. Kagayama, A. Aoba, Drug Metabol. Pharmacokinet. 4 (2002) 316.

[29] W.F. Smyth, P. Brooks, Electrophoresis 25 (2004) 1413.

[30] W.F. Smyth, Electrophoresis 26 (2005) 1334.

[31] W.F. Smyth, J. Chromatogr. B 824 (2005) 1.

[32] W.F. Smyth, J.C. Leslie, S. McClean, B. Hannigan, H.P. Mckenna, B. Doherty, C. Joyce, E. O'Kane, Rapid Commun. Mass Spectrom. 20 (2006) 1637.

[33] W.F. Smyth, Electrophoresis 27 (2006) 2051.

[34] W.F. Smyth, S. McClean, C.J. Hack, V.N. Ramachandran, B. Doherty, C. Joyce, F. O'Donnell, T.J. Smyth, P. Brooks, Trends Anal. Chem. 25 (2006) 572.

[35] S.A. Hofstadler, K.A. Sannes-Lowery, Nat. Rev. Drug Discov. 5 (2006) 585.

[36] V.V.S.R. Prasad, R. Honeyywell, J.V. Rao, N.K. Sathish, S.M.S. Kumar, Y.C. Mayur, Int. J. Mass Spectrom. 263 (2007) 148.

[37] R. Gottardo, F. Bortolotti, G.D. Paoli, J.P. Pascali, I. Miksik, F. Tagliaro, J. Chromatogr. A 1159 (2007) 185.

[38] O. Nicolas, C. Farenc, M. Calas, H.J. Vial, F. Bressole, Clin. Chem. 51 (2005) 593.

[39] F. O’Donnell, V.N. Ramachandran, W.F. Smyth, C.J. Hack, H. Patton, Anal. Chim. Acta 572 (2006) 63.

[40] P. Gomes, M.J. Araújo, M. Rodrigues, N. Vale, Z. Azevedo, J. Iley, P. Chambel, J. Morais, R. Moreira, Tetrahedron 60 (2004) 5551.

[41] M.J. Araújo, J. Bom, R. Capela, C. Casimiro, P. Chambel, P. Gomes, J. Iley, F. Lopes, J. Morais, R. Moreira, E. Oliveira, V. Rosário, N. Vale, J. Med. Chem. 48 (2005) 888

[42] P. Chambel, R. Capela, F. Lopes, J. Iley, J. Morais, L. Gouveia, J.R.G. Gomes, P. Gomes, R. Moreira, Tetrahedron 62 (2006) 9883.

[43] I. Slepukhina, T. Duelcks, H.M. Schiebel, D. Gabel, J. Organomet. Chem. 690 (2005) 2796.

[44] http://www.thermofinnigan.com.

[45] T.J. Smyth, V.N. Ramachandran, A. McGuigan, J. Hopps, W.F. Smyth, Rapid Commun. Mass Spectrom. 21 (2007) 557.

[46] W.F. Smyth, C. Joyce, V.N. Ramachandran, E. O'kane, D. Coulter, Anal. Chim. Acta 506 (2004) 203.

[47] C. Joyce, F. Smyth, V.N. Ramachandran, E. O'Kane, D.J. Coulter, J. Pharm. Biomed. Anal. 36 (2004) 465.

[48] X. Yang, Y. Xia, X. Liao, Y. Zuo, Y. Liao, H. Liu, Talanta 70 (2006) 75.

[49] H. Li, G. Yuan, Int. J. Mass Spectrom. 252 (2006) 54.

[50] K.J. Baird, S.L. Hoffman, Clin. Infect. Dis. 39 (2004) 1336. 